\title{
PEMODELAN PERUBAHAN PENGGUNAAN LAHAN KABUPATEN HUMBANG HASUNDUTAN MENGGUNAKAN CLUE-S
}

\author{
Modeling Land-Use Change in Humbang Hasundutan District Using \\ Clue-S
}

\section{Toga Pandapotan Sinurat1)*, Khursatul Munibah2), dan Dwi Putro Tejo Baskoro')}

1) Dinas Kehutanan dan Lingkungan Hidup, J1. Raya Bonandolok KM. 3,5 Kompleks Perkantoran Purba DolokDoloksanggul Kab. Humbang Hasundutan Prov. Sumatera Utara 22457

2) Departemen Ilmu Tanah dan Sumberdaya Lahan, Fakultas Pertanian, Jl. Meranti Kampus IPB Dramaga, Bogor 16680

\begin{abstract}
The growth of a region has changed land-use pattern, not only in urban areas but also rural areas such as Humbang Hasundutan regency, North Sumatra Province. As one district that newly developed since its establishment in 2003, land-use change has affected the environment such as the emergence of degraded land due to deforestation and other environmental vulnerability issues in some sub districts. CLUE-S (the Conversion of Land Use and its Effects at Small region extents) model with a combination of dynamic systems and quantification of empirical relationships between land-use and its driving factors was chosen to predict land-use change that improves an understanding of land allocation planning. The aims of this study were to analyze land-use change in Humbang Hasundutan district and predict the changes in year 2033. The results showed Humbang Hasundutan district has 5,362 hectares of forest cover loss in period of years 2003 to 2013. Land use change simulation by using scenario with restricted area policy and forest land rehabilitation can maintain forest cover over $30 \%$ and contribute to augment forest vegetation on degraded lands by $47.87 \%$ in year 2033.
\end{abstract}

Keywords: CLUE-S, degraded land, forest cover, land-use change

\begin{abstract}
ABSTRAK
Pertumbuhan suatu wilayah merubah pola penggunaan lahan tidak hanya di kawasan perkotaan (urban) akan tetapi juga terjadi pada wilayah dengan karakteristik perdesaan (rural) seperti Kabupaten Humbang Hasundutan. Sebagai salah satu kabupaten yang baru berkembang sejak terbentuk tahun 2003, perubahan penggunaan lahan di Kabupaten Humbang Hasundutan mengindikasikan terjadinya dampak negatif terhadap lingkungan seperti munculnya lahan terdegradasi akibat deforestasi dan isu kerentanan lingkungan di beberapa kecamatan yaitu erosi dan bahaya longsor. Model CLUE-S (the Conversion of Land Use and its Effects at Small region extents) adalah suatu pemodelan spasial untuk mensimulasikan perubahan penggunaan lahan berdasarkan kuantifikasi hubungan secara empirik berbagai faktor pendorong untuk memprediksi perubahan penggunaan lahan di masa yang akan datang. Hasil analisis perubahan penggunaan lahan menunjukkan bahwa di Kabupaten Humbang Hasundutan terjadi deforestasi seluas 5,362 hektar selama periode tahun 2003-2013. Proyeksi perubahan penggunaan lahan berdasarkan laju perubahan alami menunjukkan luas penggunaan lahan hutan pada akhir tahun 2033 hanya tersisa sebesar 27.5\% dari luas wilayah Kabupaten Humbang Hasundutan. Kondisi ini menjadi tidak sesuai dengan proporsi luas hutan yang dialokasikan menurut pola ruang dalam penyusunan Rencana Tata Ruang Wilayah (RTRW) yaitu sebesar $30 \%$ dari luas wilayah. Pemodelan menggunakan skenario kawasan terbatas dan alokasi rehabilitasi lahan hutan dapat mempertahankan hutan lebih dari $30 \%$ dan berkontribusi mengembalikan penutupan vegetasi hutan pada lahan terdegradasi sebesar $47.87 \%$.
\end{abstract}

Kata kunci: CLUE-S, lahan terdegradasi, hutan, perubahan penggunaan lahan

\section{PENDAHULUAN}

Pengalokasian lahan berdasarkan keterkaitan fungsi dan kemampuan lahan diharapkan dapat mengendalikan perubahan penggunaan lahan serta meminimalkan dampak negatif terhadap lingkungan. Penggunaan lahan yang tidak terkendali sebagaimana dikemukakan Rossiter (1996) dapat mengarahkan pada inefisiensi pemanfaatan sumber daya alam, rusaknya sumber daya lahan, kemiskinan dan masalah sosial lainnya.

Pertumbuhan wilayah Kabupaten Humbang Hasundutan terbilang relatif pesat dibandingkan dengan kabupaten di sekitarnya. Hal ini ditunjukkan dengan adanya peningkatan positif nilai PDRB dari 5.32\% tahun 2009 naik menjadi 6.03\% tahun 2013 (BPS, 2013). Perkembangan ini pada dasarnya telah merubah pola penggunaan lahan di Kabupaten Humbang Hasundutan 
ditandai dengan munculnya pusat-pusat kegiatan di setiap kecamatan dan terbentuknya permukiman-permukiman baru, akan tetapi perubahan tersebut juga mengindikasikan adanya dampak negatif terhadap lingkungan yaitu timbulnya lahan terdegradasi. Menurut data spasial lahan kritis BPDAS WU (2013), di Kabupaten Humbang Hasundutan terdapat lahan terdegradasi seluas 27,870 hektar (11.2\%) dengan kategori sangat kritis; 68,274 hektar (27.5\%) kategori kritis; 88,890 hektar (35.9\%) agak kritis; 40,453 hektar (16.3\%) potensial kritis; dan 22,365 hektar $(9 \%)$ termasuk tidak kritis.

Munculnya lahan terdegradasi menyebabkan turunnya kualitas suatu lahan dan mengarah pada rendahnya produktivitas dari lahan tersebut. Hal ini sesuai dengan data BPS (2013) tahun 2007 s.d 2011, bahwa produksi tanaman pangan di Kabupaten Humbang Hasundutan mengalami penurunan khususnya produksi padi (gabah kering giling) yang semula 111,181 ton menjadi 103,410 ton. Indikasi lainnya terkait isu kerentanan lingkungan di beberapa lokasi pada daerah perbukitan seperti Kecamatan Pakkat, Parlilitan, Tarabintang, Onanganjang dan Baktiraja pernah dinyatakan waspada longsor oleh BPBD Humbang Hasundutan.

Kim et al. (2011) menyebutkan suatu prediksi perubahan penggunaan lahan dapat menyediakan peluang untuk menghadapi permasalahan lingkungan dan perubahan regional di masa depan. Belum diketahuinya perubahan penggunaan lahan di Kabupaten Humbang Hasundutan dan faktor-faktor yang mempengaruhi perubahan tersebut mendasari pentingnya penelitian dilakukan sekaligus memproyeksikan perubahan penggunaan lahan di masa yang akan datang dalam rangka membangun kebijakan terkait perencanaan tata ruang dan alokasi penggunaan lahan.

Kerangka awal model Conversion of Land Use and Its Effects (CLUE) yang dikembangkan Veldkamp dan Fresco (1996), Verburg et al. (1999), dan Verburg et al. (2002) dibuat untuk mensimulasikan perubahan penggunaan lahan untuk wilayah dengan cakupan yang sangat luas (skala global). Oleh karena perbedaan representasi data dan fitur lain untuk diaplikasikan secara regional, model CLUE tidak dapat diterapkan, sehingga dikembangkan pendekatan pemodelan CLUE-S (the Conversion of Land Uses and its Effects at Small region extent) dengan menggunakan resolusi spasial tidak lebih dari 1 x $1 \mathrm{~km}$. Simulasi perubahan penggunaan lahan menggunakan CLUE-S dapat dijalankan dengan berbagai kondisi skenario. Penerapan menggunakan skenario yang berbeda-beda dapat mendukung dalam mengeksplorasi perubahan penggunaan lahan di masa yang akan datang (Verburg et al., 2002).

Penelitian ini bertujuan untuk memproyeksikan perubahan penggunaan lahan Kabupaten Humbang Hasundutan pada Tahun 2033 dengan menerapkan kondisi skenario yang dapat mempertahankan proporsi hutan sesuai ketentuan pola ruang berdasarkan UU No 26 tahun 2007 tentang Penataan Ruang.

\section{BAHAN DAN METODE}

Kabupaten Humbang Hasundutan merupakan salah satu kabupaten di wilayah Provinsi Sumatera Utara dengan luas wilayah 247,848 hektar terdiri atas 10 kecamatan, 153 desa dan 1 kelurahan, dengan jumlah penduduk sebanyak 176,429 jiwa (BPS, 2013). Wilayah secara geografis terletak pada posisi $98^{\circ} 15.08^{\prime}$ - $98^{\circ} 57.88^{\prime}$ Bujur Timur dan $1^{\circ}$ 59.91' - 2० 30.84' Lintang Utara (Gambar 1) dengan karakteristik wilayah dataran tinggi pegunungan pada ketinggian 65 s.d 2,025 m dpl.

Bahan yang digunakan dalam penelitian ini adalah citra Landsat 7 ETM+ Tahun 2003 dan citra Landsat 8 OLI Tahun 2013. Peta administrasi, jaringan jalan, curah hujan diperoleh dari data tematik RTRW Kabupaten Humbang Hasundutan Tahun 2011-2013 skala 1 : 100,000. Data kependudukan dan jumlah rumah tangga pertanian diperoleh dari BPS Humbang Hasundutan Tahun 2013. Data elevasi dan lereng diperoleh dari data SRTM (Shuttle Radar Topography Mission) resolusi 90 meter. Peta penetapan moratorium izin baru pada hutan primer dan lahan gambut skala $1: 250,000$ bersumber dari Kementrian Lingkungan Hidup dan Kehutanan Tahun 2015. Peta Satuan Lahan dan Tanah Skala 1 : 250,000 Lembar 0618 Sidikalang, Sumatera bersumber dari Puslittan Tahun 1989. Peta Sungai dan Peta Lahan Kritis Skala 1 : 100,000 bersumber dari BPDAS Wampu SeiUlar, Medan. Data sasaran kegiatan Rehabilitasi Hutan dan Lahan (RHL) menurut Buku Rencana Pengelolaan Rehabilitasi Hutan dan Lahan (RP-RHL) Kabupaten Humbang Hasundutan Tahun 2013 - 2017. Alat yang digunakan dalam penelitian ini adalah perangkat lunak Dyna CLUE-S v2.0, Notepad, pengolah data penginderaan jauh, pengolah peta dan pengolah data statistik.

Klasifikasi penggunaan lahan diperoleh melalui interpretasi visual terhadap citra satelit dalam dua titik tahun yaitu Tahun 2003 dan Tahun 2013 dan dievaluasi berdasarkan nilai overall accuracy dan kappa coefficient melalui konfirmasi 100 titik uji (groundtruth) terhadap aktual di lapangan dan citra resolusi tinggi Google Earth.

Analisis faktor-faktor yang mempengaruhi perubahan penggunaan lahan dilakukan menggunakan regresi logistik biner dijalankan dengan metode forward stepwise yang bertujuan untuk mengeliminasi faktor-faktor pengaruh yang tidak signifikan dalam model. Regresi logistik biner adalah model regresi dimana variabel dependen bersifat biner atau dikotomi. Fungsi regresi merupakan suatu respon monotonic garis kurva dibatasi antara 0 dan 1 dengan fungsi logistik pada persamaan,

$$
p_{i}=E(Y)=\frac{\operatorname{Exp}\left(\beta_{0}+\beta_{1} X_{1}+\beta_{2} X_{2}+\cdots+\beta_{n} X_{i}\right)}{1+\operatorname{Exp}\left(\beta_{0}+\beta_{1} X_{1}+\beta_{2} X_{2}+\cdots+\beta_{n} X_{i}\right)}
$$

dimana pi adalah nilai probabilitas peningkatan sel penggunaan lahan sedangkan $\mathrm{E}(\mathrm{Y})$ perolehan nilai dari variabel dependen biner $\mathrm{Y}, \quad \beta 0$ adalah nilai konstan yang diestimasi, $\beta \mathrm{n}$ adalah koefisien yang diestimasi dari masing-masing variabel independen $\mathrm{Xi}$ (Pontius dan Schneider, 2001). Variabel dependen yang terdiri dari setiap kelas penggunaan lahan ditransformasikan dalam peta raster biner $(0$ dan 1$)$ dengan resolusi piksel $100 \times 100$ meter. Nilai 1 menunjukkan satu kelas penggunaan lahan sedangkan nilai 0 tidak terdapat penggunaan lahan. Variabel independen berupa faktor-faktor biofisik dan sosial ekonomi diklasifikasikan berdasarkan kelas kategori masing-masing tipe data dari nilai terkecil sampai terbesar dengan metode peng-kelasan natural breaks dalam format 
raster dengan resolusi piksel yang sama dengan kelas penggunaan lahan. Untuk memperoleh nilai numerik tiap sel raster dari masing-masing variabel, data raster seluruhnya dikonversi ke dalam format ASCII text dan kombinasi nilai sel antar variabel ditabulasikan berdasarkan formulasi regresi logistik serta selanjutnya diolah menggunakan aplikasi statistik.

Proyeksi perubahan penggunaan lahan didasarkan pada pola perubahan pada minimal dua titik waktu ( $\mathrm{t} 0$ dan t1) untuk menghasilkan pola perubahan penggunaan lahan pada waktu (t2). Simulasi perubahan menggunakan model CLUE-S diproyeksi sampai Tahun 2033 (baseline 20 tahun berdasarkan jangka waktu Rencana Tata Ruang Wilayah). Pengaturan dilakuan terhadap paramater yang menjadi input dalam aplikasi CLUE-S terdiri atas kelas penggunaan lahan, matriks konversi, elastisitas konversi, kebutuhan lahan, karakteristik lokasi penggunaan lahan dan kondisi skenario (Verburg, 2010). Seluruh rangkaian proses analisis diilustrasikan dengan Gambar 2.

\section{HASIL DAN PEMBAHASAN}

\section{Perubahan Penggunaan Lahan Kabupaten Humbang Hasundutan}

Interpretasi penggunaan lahan tahun 2003 dan 2013 menghasilkan sembilan kelas penggunaan lahan yaitu belukar, rawa/ gambut, hutan, hutan tanaman, lahan terbuka, permukiman, pertanian lahan kering, sawah dan tubuh air (Gambar 3). Masing-masing nilai overall accuracy dan kappa coefficient klasifikasi penggunaan lahan terkonfirmasi untuk tahun 2003 sebesar $0.95 \%$ dan 0.91, sedangkan untuk tahun 2013 sebesar $0.93 \%$ dan 0.90 . Hal ini menunjukkan hasil interpretasi sangat baik dan dapat dilanjutkan untuk analisis selanjutnya.

Perubahan penggunaan lahan di Kabupaten Humbang Hasundutan periode 2003 s.d 2013 terjadi pada areal seluas 13,510 hektar yang terdiri dari penggunaan lahan yang mengalami penurunan luas terjadi hutan sebesar $6.4 \%$, rawa/gambut sebesar $44 \%$ dan lahan terbuka sebesar 5\% sedangkan peningkatan luas terjadi pertanian lahan kering sebesar 5.8\%, belukar sebesar 19\%, lahan terbangun sebesar $39.4 \%$ dan sawah sebesar $3 \%$.
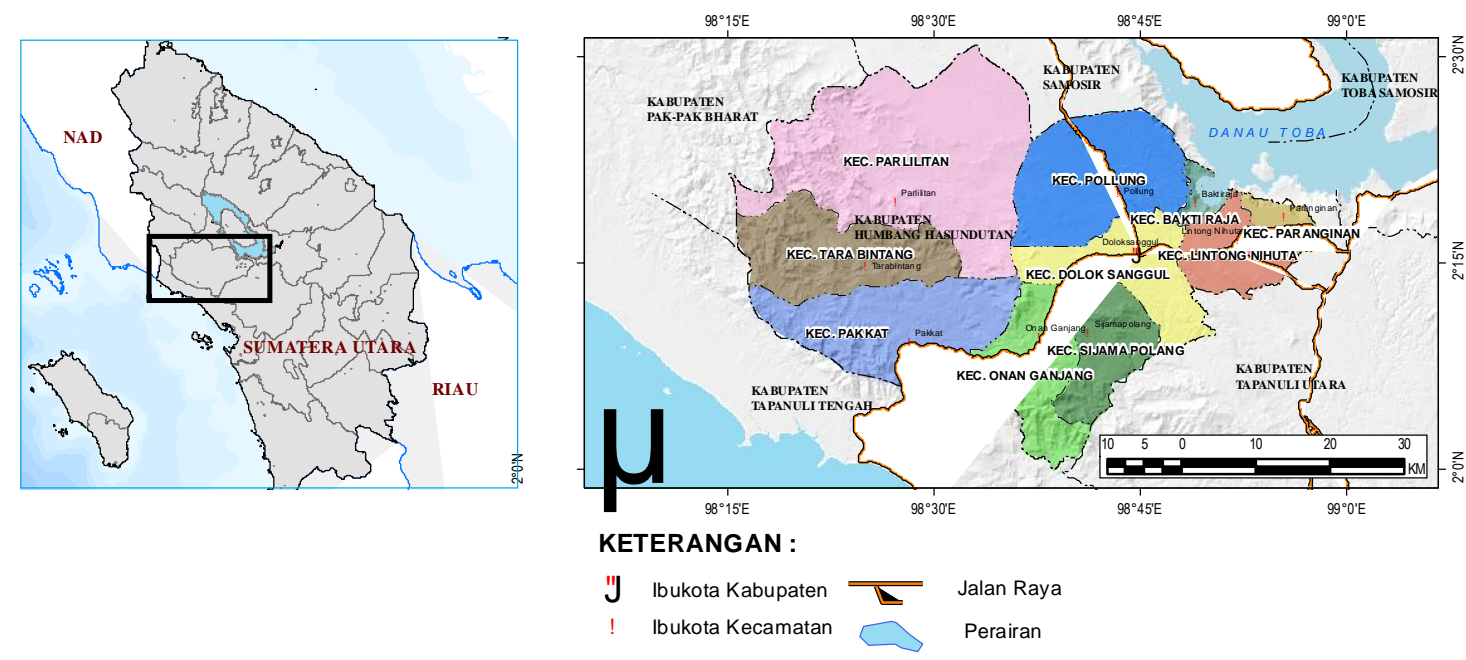

Gambar 1. Wilayah studi

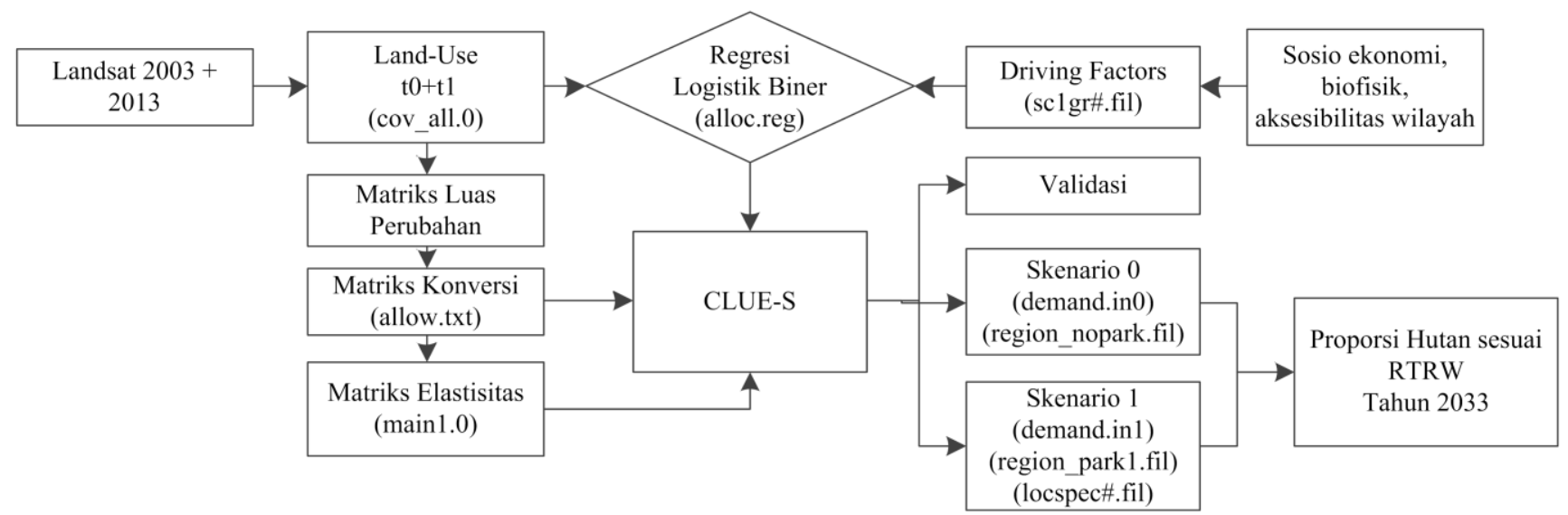

Gambar 2. Metode analisis perubahan pengunaan dengan Model CLUE-S 


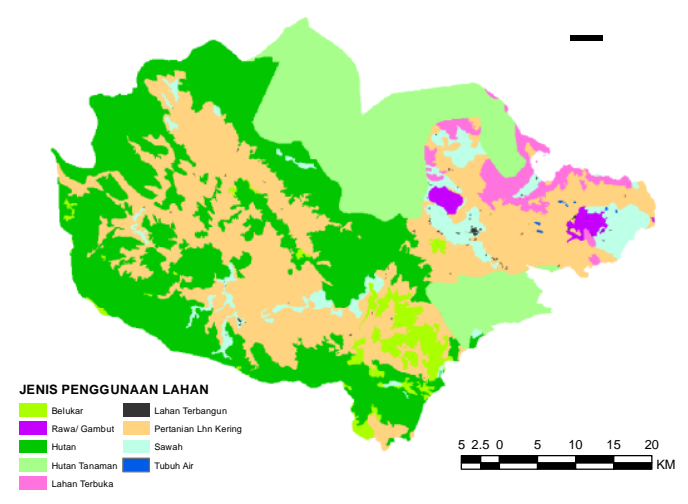

(a) Tahun 2003

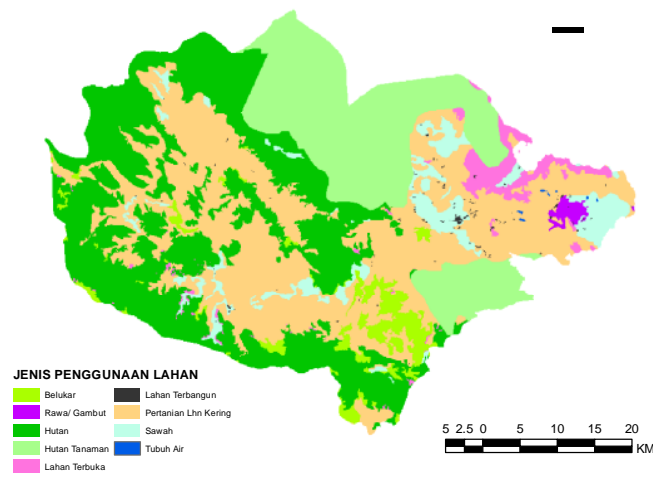

(b) Tahun 2013

Gambar 3. Klasifikasi penggunaan lahan

Perubahan penggunaan lahan pada periode ini menujukkan terjadinya deforestasi hutan seluas 5,362 hektar dengan laju penyusutan 536.2 hektar per tahunnya. Pola perubahan penggunaan lahan hutan adalah berubah menjadi pertanian lahan kering, belukar, lahan terbuka dan sawah. Perbandingan perubahan luas masing-masing kelas penggunaan lahan disajikan dalam Tabel 1.
Nilai ROC dalam model regresi diperoleh untuk rawa/gambut (0.995), lahan terbangun (0.949), hutan (0.905), lahan terbuka (0.896), sawah $(0.877)$, pertanian lahan kering (0.861), dan belukar (0.834). Hutan tanaman dan tubuh air tidak diregresikan karena bersifat statis (tidak mengalami perubahan luas) dan nilai konstanta ditetapkan sebesar 0.7 (Verburg, 2010).

Tabel 1. Perubahan luas penggunaan lahan periode tahun 2003 s.d 2013

\begin{tabular}{|c|c|c|c|c|c|c|c|}
\hline \multirow[t]{2}{*}{ No. } & \multirow[t]{2}{*}{ Jenis Penggunaan Lahan } & \multicolumn{2}{|c|}{2003} & \multicolumn{2}{|c|}{2013} & \multicolumn{2}{|c|}{ Luas Perubahan } \\
\hline & & (ha) & $\%$ & (ha) & $\%$ & (ha) & $\%$ \\
\hline 1 & Belukar & 8,074 & 3.3 & 9,606 & 3.9 & 1,532 & 19.0 \\
\hline 2 & Rawa/ Gambut & 2,330 & 0.9 & 1,304 & 0.5 & $-1,026$ & -44.0 \\
\hline 3 & Hutan & 83,768 & 33.8 & 78,406 & 31.6 & $-5,362$ & -6.4 \\
\hline 4 & Hutan Tanaman & 51,613 & 20.8 & 51,613 & 20.8 & 0 & 0.0 \\
\hline 5 & Terbuka & 7,351 & 3.0 & 6,984 & 2.8 & -367 & -5.0 \\
\hline 6 & Terbangun & 340 & 0.1 & 474 & 0.2 & 134 & 39.4 \\
\hline 7 & Pertanian Lahan Kering & 80,733 & 32.6 & 85,410 & 34.5 & 4,677 & 5.8 \\
\hline 8 & Sawah & 13,520 & 5.5 & 13,932 & 5.6 & 412 & 3.0 \\
\hline 9 & Air & 119 & 0.0 & 119 & 0.0 & 0 & 0.0 \\
\hline & Total Luas (ha) & 247,848 & 100 & 247,848 & 100 & 13,510 & 5.5 \\
\hline
\end{tabular}

\section{Faktor-faktor yang Mempengaruhi Perubahan Penggunaan Lahan}

Faktor-faktor yang mempengaruhi perubahan penggunaan lahan adalah faktor yang diseleksi dari aspek sosial ekonomi yaitu jumlah penduduk (jiwa) dan rumah tangga pertanian (RT), sedangkan aspek biofisik terdiri atas, curah hujan $\left(\mathrm{mm} \mathrm{thn}^{-1}\right)$, elevasi $(\mathrm{m} \mathrm{dpl})$, slope $(\%)$ dan jenis tanah serta aspek aksesibilitas jarak dari ibukota kabupaten, jarak dari kota kecamatan, jarak dari jalan utama, jarak dari sungai besar yang dihasilkan menggunakan metode euclidean distance.

Hubungan berbagai faktor yang mempengaruhi peningkatan sel tiap jenis penggunaan lahan dapat diketahui dari nilai koefisien beta $(\beta)$ pada Tabel $2 \mathrm{a}$ dan nilai peningkatan peluang pada $\operatorname{Exp}(\beta)$ pada Tabel $2 \mathrm{~b}$. Ketepatan hasil regresi dievaluasi berdasarkan nilai ROC (Relative Operating Characteristic) masing-masing penggunaan lahan. Nilai ROC $>0.5$ menunjukkan pengaruh faktor-faktor penduga dalam model tidak terjadi secara kebetulan (Pontius dan Schneider, 2001).

\section{Model Perubahan Penggunaan Lahan}

Penggunaan lahan tahun 2003 dan tahun 2013 ditranformasikan menjadi ASCII text dengan penamaan file (cov_all.0). Matriks konversi adalah nilai perubahan yang diperkenankan terjadi pada setiap jenis penggunaan lahan, dihasilkan dari tabulasi silang penggunaan lahan pada dua titik tahun dan disusun dalam format text dengan nama (allow.txt). Nilai 0 menandakan jenis penggunaan lahan tidak boleh berubah sedangkan nilai 1 dapat berubah. Matriks konversi penggunaan lahan disajikan pada Tabel 3. Elastistitas konversi berhubungan dengan mudah tidaknya suatu penggunaan lahan terkonversi dan mengalami perubahan kembali ke sifat semula. Nilai elastisitas berada pada rentang 0 dan 1 , mendekati 1 diartikan jenis penggunaan lahan tersebut tidak mudah berubah sebaliknya nilai elastisitas 0 menandakan jenis tersebut mudah terkonversi (Verburg, 2010). Nilai elastisitas masing-masing penggunaaan lahan pada Tabel 4 diatur dalam file (alloc1.reg). 
Tabel 2a. Nilai koefisien beta $(\beta)$ pengaruh berbagai faktor terhadap kelas penggunaan lahan

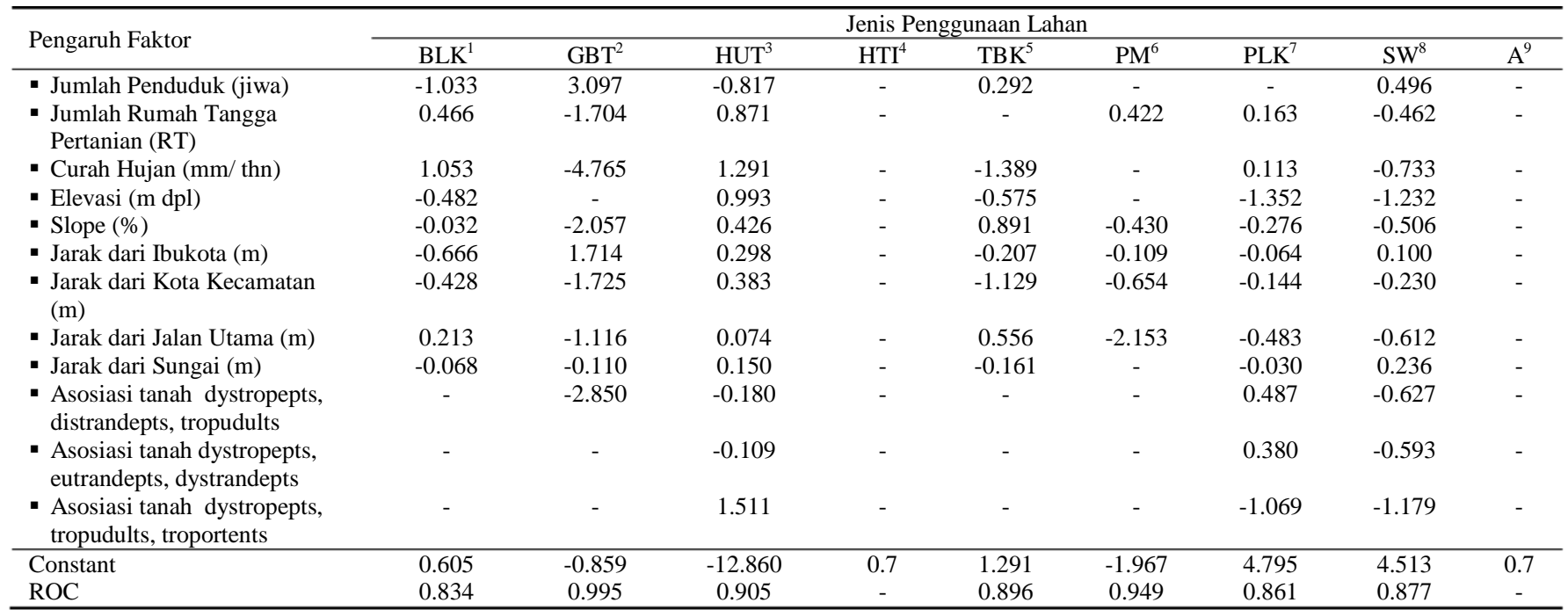

${ }^{1}$ BLK (Belukar), ${ }^{2}$ GBT (Rawa/ gambut), ${ }^{3}$ HUT (Hutan), ${ }^{4}$ HTI (Hutan Tanaman), ${ }^{5}$ TBK (Lahan Terbuka), ${ }^{6}$ PM (Lahan Terbangun/ Permukiman), ${ }^{7}$ PLK (Pertanian Lahan Kering), ${ }^{8} \mathrm{SW}$ (Sawah), ${ }^{9} \mathrm{~A}$ (Tubuh Air)

Tabel 2b. Nilai peluang Exp $(\beta)$ kelas penggunaan lahan

\begin{tabular}{|c|c|c|c|c|c|c|c|c|c|}
\hline \multirow{2}{*}{ Pengaruh Faktor } & \multicolumn{9}{|c|}{ Jenis Penggunaan Lahan } \\
\hline & $\mathrm{BLK}^{1}$ & $\mathrm{GBT}^{2}$ & $\mathrm{HUT}^{3}$ & $\mathrm{HTI}^{4}$ & $\mathrm{TBK}^{5}$ & $\mathrm{PM}^{6}$ & $\mathrm{PLK}^{7}$ & $\mathrm{SW}^{8}$ & $\mathrm{~A}^{9}$ \\
\hline - Jumlah Penduduk (jiwa) & 0.356 & 22.14 & 0.441 & - & 1.338 & - & - & 1.642 & - \\
\hline $\begin{array}{l}\text { - Jumlah Rumah Tangga } \\
\text { Pertanian (RT) }\end{array}$ & 1.593 & 0.182 & 2.388 & - & - & 1.525 & 1.177 & 0.63 & - \\
\hline - Curah Hujan (mm/ thn) & 2.866 & 0.009 & 3.636 & - & 0.249 & - & 1.12 & 0.48 & - \\
\hline - Elevasi (m dpl) & 0.618 & & 2.698 & - & 0.563 & - & 0.259 & 0.292 & - \\
\hline - Slope $(\%)$ & 0.969 & 0.128 & 1.531 & - & 2.436 & 0.651 & 0.759 & 0.603 & - \\
\hline - Jarak dari Ibukota (m) & 0.514 & 5.552 & 1.346 & - & 0.813 & 0.897 & 0.938 & 1.105 & - \\
\hline - Jarak dari Jalan Utama (m) & 1.237 & 0.328 & 1.077 & - & 1.744 & 0.116 & 0.617 & 0.542 & - \\
\hline - Jarak dari Sungai (m) & 0.935 & 0.895 & 1.161 & - & 0.852 & - & 0.971 & 1.266 & - \\
\hline $\begin{array}{l}\text { Asosiasi tanah dystropepts, } \\
\text { distrandepts, tropudults }\end{array}$ & - & 0.058 & 0.835 & - & - & - & 1.628 & 0.534 & - \\
\hline $\begin{array}{l}\text { Asosiasi tanah dystropepts, } \\
\text { eutrandepts, dystrandepts }\end{array}$ & - & - & 0.896 & - & - & - & 1.463 & 0.553 & - \\
\hline $\begin{array}{l}\text { - Asosiasi tanah dystropepts, } \\
\text { tropudults, troportents }\end{array}$ & - & - & 4.531 & - & - & - & 0.343 & 0.307 & - \\
\hline
\end{tabular}

${ }^{1}$ BLK (Belukar), ${ }^{2}$ GBT (Rawa/ gambut), ${ }^{3}$ HUT (Hutan), ${ }^{4} \mathrm{HTI}$ (Hutan Tanaman), ${ }^{5}$ TBK (Lahan Terbuka), ${ }^{6} \mathrm{PM}$ (Lahan Terbangun/ Permukiman), ${ }^{7}$ PLK (Pertanian Lahan Kering), ${ }^{8} \mathrm{SW}$ (Sawah), ${ }^{9} \mathrm{~A}$ (Tubuh Air)

Tabel 3. Matriks konversi penggunaan lahan

\begin{tabular}{|c|c|c|c|c|c|c|c|c|c|}
\hline Penggunaan Lahan & $\mathrm{BLK}^{1}$ & $\mathrm{GBT}^{2}$ & $\mathrm{HUT}^{3}$ & $\mathrm{HTI}^{4}$ & $\mathrm{TBK}^{5}$ & $\mathrm{PM}^{6}$ & $\mathrm{PLK}^{7}$ & $\mathrm{SW}^{8}$ & $\mathrm{~A}^{9}$ \\
\hline $\mathrm{BLK}^{1}$ & 1 & 0 & 0 & 0 & 1 & 0 & 0 & 0 & 0 \\
\hline $\mathrm{GBT}^{2}$ & 0 & 1 & 0 & 0 & 0 & 1 & 1 & 1 & 0 \\
\hline $\mathrm{HUT}^{3}$ & 1 & 0 & 1 & 0 & 1 & 0 & 1 & 1 & 0 \\
\hline $\mathrm{TBK}^{5}$ & 0 & 0 & 0 & 0 & 1 & 1 & 1 & 0 & 0 \\
\hline $\mathrm{PM}^{6}$ & 0 & 0 & 0 & 0 & 0 & 1 & 0 & 0 & 0 \\
\hline $\mathrm{PLK}^{7}$ & 1 & 0 & 1 & 0 & 1 & 1 & 1 & 1 & 0 \\
\hline
\end{tabular}

${ }^{1}$ BLK (Belukar), ${ }^{2}$ GBT (Rawa/ gambut), ${ }^{3}$ HUT (Hutan), ${ }^{4} \mathrm{HTI}$ (Hutan Tanaman), ${ }^{5}$ TBK (Lahan Terbuka), ${ }^{6} \mathrm{PM}$ (Lahan Terbangun/ Permukiman), ${ }^{7}$ PLK (Pertanian Lahan Kering), ${ }^{8} \mathrm{SW}$ (Sawah), ${ }^{9} \mathrm{~A}$ (Tubuh Air)

Tabel 4. Nilai elastisitas jenis penggunaan lahan

\begin{tabular}{|c|c|c|c|c|c|c|c|c|c|}
\hline & \multicolumn{9}{|c|}{ Kelas Penggunaan Lahan } \\
\hline & $\mathrm{BLK}^{1}$ & $\mathrm{GBT}^{2}$ & $\mathrm{HUT}^{3}$ & $\mathrm{HTI}^{4}$ & $\mathrm{TBK}^{5}$ & $\mathrm{PM}^{6}$ & $\mathrm{PLK}^{7}$ & $\mathrm{SW}^{8}$ & $\mathrm{~A}^{9}$ \\
\hline Elastisitas Konversi & 0.5 & 0.4 & 0.7 & 1 & 0.3 & 1 & 0.5 & 0.8 & 1 \\
\hline
\end{tabular}

${ }^{1}$ BLK (Belukar), ${ }^{2}$ GBT (Rawa/ gambut), ${ }^{3} \mathrm{HUT}$ (Hutan), ${ }^{4} \mathrm{HTI}$ (Hutan Tanaman), ${ }^{5} \mathrm{TBK}$ (Lahan Terbuka), ${ }^{6} \mathrm{PM}$ (Lahan Terbangun/ Permukiman), ${ }^{7} \mathrm{PLK}$ (Pertanian Lahan Kering), ${ }^{8} \mathrm{SW}$ (Sawah), ${ }^{9} \mathrm{~A}$ (Tubuh Air) 
Kebutuhan penggunaan lahan adalah tabulasi ratarata luas perubahan penggunaan lahan per tahun prediksi yang disusun dalam format text dengan penamaan (demand.in) dan dimodifikasi sesuai dengan kebutuhan skenario.

\section{Validasi Model}

Validasi model CLUE-S menggunakan penggunaan lahan tahun 2003 memprediksi tahun 2013 dan dibandingkan dengan penggunaan lahan aktual tahun 2013. Simulasi ini menghasilkan nilai Kappa sebesar 0.96 dari tabulasi silang masing-masing kelas penggunaan lahan. Hal ini menunjukkan model sangat baik dan dapat dilanjutkan untuk simulasi proyeksi perubahan penggunaan lahan. Penggunaan lahan hasil simulasi untuk validasi model ditunjukan pada Gambar 4.
Kabupaten Humbang Hasundutan ditetapkan moratorium izin baru (Gambar 5) seluas 2,202.6 hektar untuk kawasan bergambut dan seluas 60,085.6 hektar berupa kawasan hutan primer (Kemenlinghut, 2015). Rehabilitasi hutan dialokasikan seluas 500 hektar per tahun yang ditetapkan berdasarkan data sasaran rehabilitasi hutan menurut Buku Rencana Pengelolaan Rehabilitasi Hutan dan Lahan Tahun 2013 - 2017 Kabupaten Humbang Hasundutan (Dishutlindup, 2013). Gambar 6 menunjukkan lokasi spesifik rehabilitasi hutan pada lahan sangat kritis. Perbandingan kebutuhan luas dan alokasi lahan setiap skenario diilustrasikan dalam Gambar 7 menurut hasil tabulasi rata-rata perubahan penggunaan lahan per tahunnya sesuai jangka waktu proyeksi.

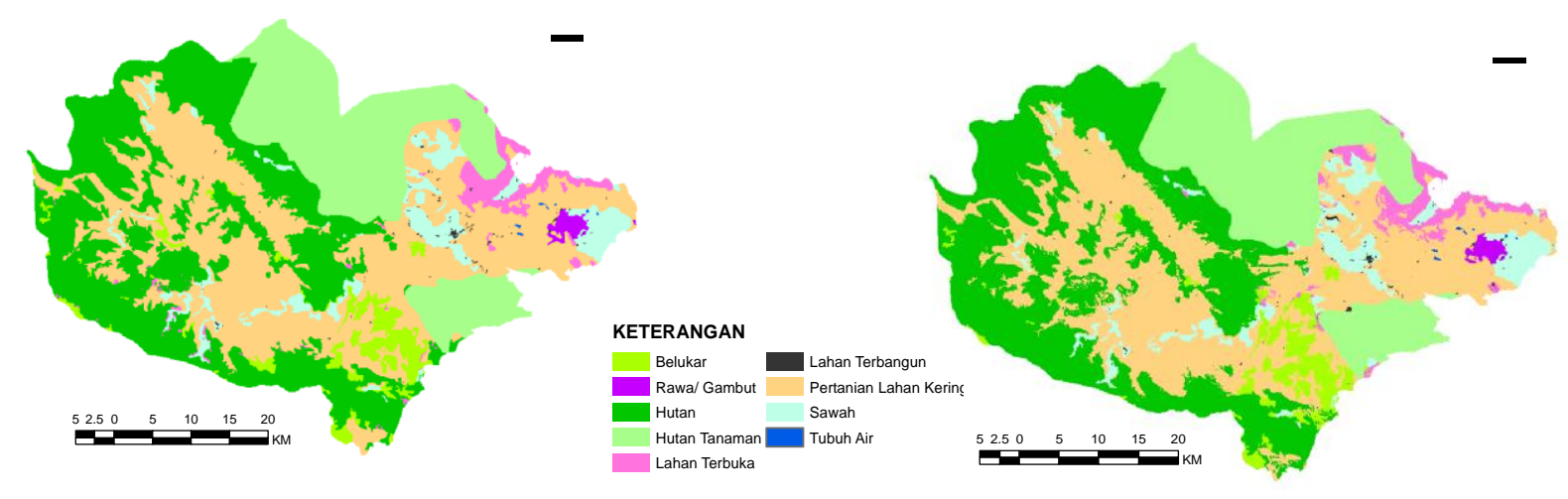

Gambar 4. Penggunaan lahan hasil validasi model

\section{Skenario dalam Simulasi}

Model simulasi dijalankan dengan dua kondisi skenario. Skenario 0 merupakan kondisi laju perubahan alami tanpa adanya larangan konversi untuk masingmasing penggunaan lahan. Skenario 1 disusun dengan menetapkan areal yang tidak diperkenankan terjadi perubahan berdasarkan peta moratorium izin baru pada hutan primer dan kawasan bergambut serta mengalokasikan rehabilitasi hutan pada lahan sangat kritis.

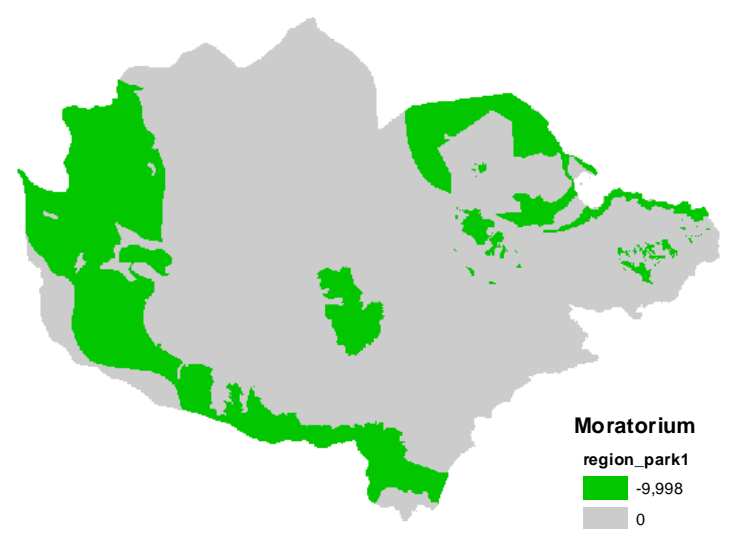

Gambar 5. Kawasan moratorium izin pada hutan primer dan kawasan bergambut

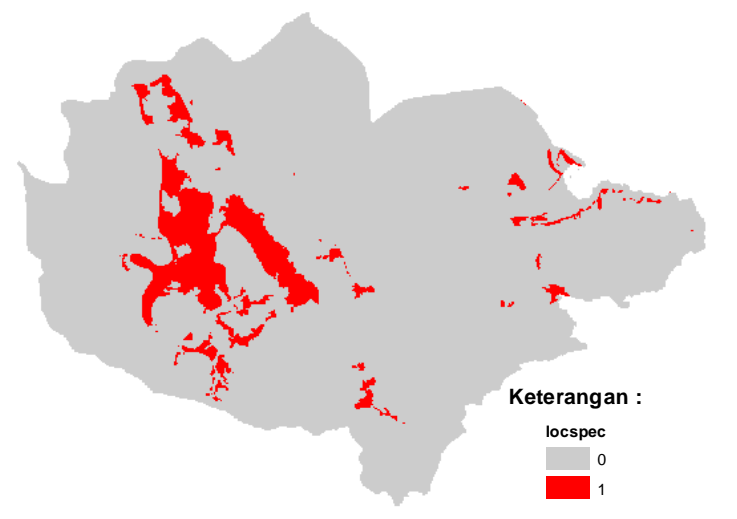

Gambar 6. Lahan terdegradasi dengan kategori sangat kritis

\section{Proyeksi Perubahan Penggunaan Lahan Tahun 2033}

Hasil simulasi perubahan penggunaan lahan untuk proyeksi tahun 2033 disajikan pada Gambar 8. Tabel 5 menunjukkan bahwa simulasi dengan laju perubahan alami (skenario 0) mengalami perubahan areal terluas yaitu sebesar 22,400 hektar sedangkan perubahan lahan pada skenario 1 hanya seluas 2,036 hektar. 


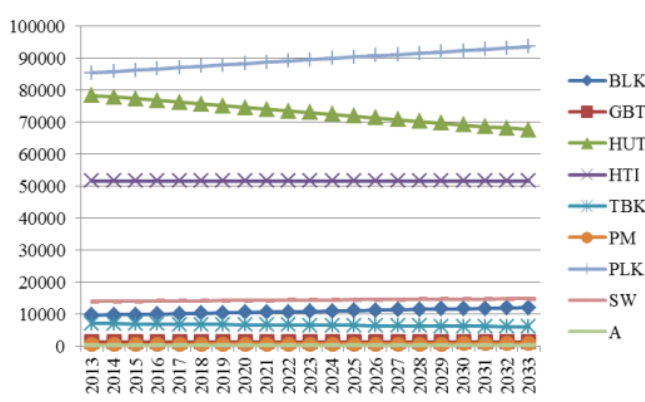

demand.ino (Skenario 0)

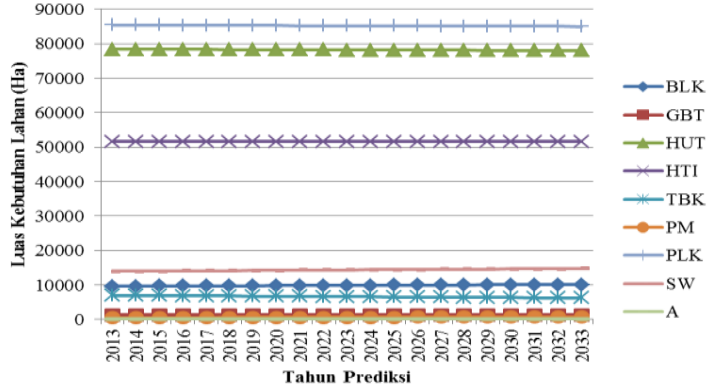

demand.in1(Skenario 1)

Gambar 7. Kebutuhan penggunaan lahan proyeksi tahun 2033

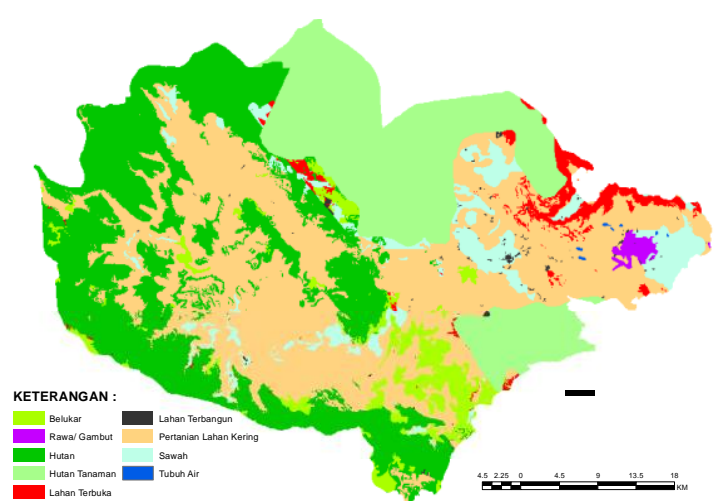

(a) Skenario 0

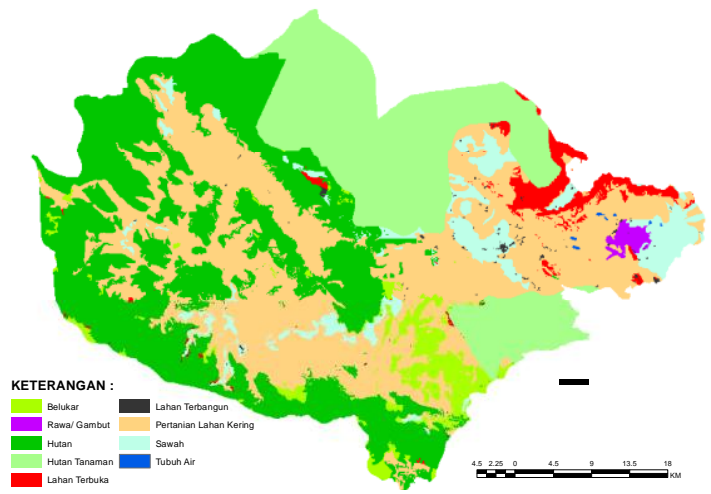

(b) Skenario 1

Gambar 8. Proyeksi penggunaan lahan tahun 2033

Melalui pemodelan spasial menggunakan CLUE-S, proyeksi perubahan penggunaan lahan pada tahun 2033 berdasarkan skenario 0 menunjukkan bahwa deforestasi meningkat seluas 10,274 hektar ke wilayah barat Kabupaten Humbang Hasundutan sehingga luas areal berhutan tersisa sebesar $27.5 \%$. Namun, skenario 1 menunjukkan deforestasi dapat ditekan menjadi seluas 286 hektar dan luas areal berhutan dapat dipertahankan sampai $31.5 \%$
Simulasi CLUE-S dengan kebijakan kawasan terbatas dan rehabilitasi hutan (skenario 1) dapat mengembalikan penutupan vegetasi hutan pada lahan sangat sangat kritis sebesar $42.87 \%$. Menurut Peraturan Menteri Kehutanan Nomor P.32/ Menhut-II/ 2009 tentang Tata Cara Penyusunan Rencana Teknik Rehabilitasi Hutan dan Lahan Daerah Aliran Sungai (RTKRHL-DAS) bahwa penilaian kriteria lahan kritis berdasarkan tutupan vegetasi mencapai $41-60 \%$ termasuk dalam kelas kategori sedang. Kontribusi tutupan vegetasi masing-masing skenario disajikan dalam Tabel 6.

Tabel 5. Perubahan luas penggunaan lahan pada masing-masing kondisi skenario

\begin{tabular}{|c|c|c|c|c|c|c|c|}
\hline \multirow[t]{2}{*}{ No } & \multirow[t]{2}{*}{$\mathrm{PL}^{1}$} & \multicolumn{2}{|c|}{ Skenario 0} & \multirow{2}{*}{$\operatorname{Prb}^{2}$ (ha) } & \multicolumn{2}{|c|}{ Skenario 1} & \multirow{2}{*}{$\operatorname{Prb}^{2}$ (ha) } \\
\hline & & (ha) & $\%$ & & (ha) & $\%$ & \\
\hline 1 & $\mathrm{BLK}^{3}$ & 11,914 & 4.8 & 2,308 & 9,791 & 4.0 & 185 \\
\hline 2 & $\mathrm{GBT}^{4}$ & 1,304 & 0.5 & 0 & 1,285 & 0.5 & -19 \\
\hline 4 & $\mathrm{HTI}^{6}$ & 51,613 & 20.8 & 0 & 51,613 & 20.8 & 0 \\
\hline 5 & $\mathrm{TBK}^{7}$ & 6,058 & 2.4 & -926 & 6,271 & 2.5 & -713 \\
\hline 6 & $\mathrm{PM}^{8}$ & 690 & 0.3 & 216 & 688 & 0.3 & 214 \\
\hline 7 & $\mathrm{PLK}^{9}$ & 93,251 & 37.6 & 7,841 & 85,561 & 34.5 & 151 \\
\hline 9 & $\mathrm{~A}^{11}$ & 119 & 0.0 & 0 & 119 & 0.0 & 0 \\
\hline \multicolumn{2}{|c|}{ Total (ha) } & 247,848 & 100 & 22,400 & 247,848 & 100 & 2,036 \\
\hline
\end{tabular}

${ }^{1}$ PL (Penggunaan Lahan), ${ }^{2}$ Prb (Luas Perubahan), ${ }^{3}$ BLK (Belukar), ${ }^{4} \mathrm{GBT}$ (Rawa/ gambut), ${ }^{5} \mathrm{HUT}$ (Hutan), ${ }^{6} \mathrm{HTI}$ (Hutan Tanaman), ${ }^{7} \mathrm{TBK}(\mathrm{Lahan}$

Terbuka), ${ }^{8} \mathrm{PM}$ (Lahan Terbangun/ Permukiman), ${ }^{9} \mathrm{PLK}$ (Pertanian Lahan Kering), ${ }^{10} \mathrm{SW}$ (Sawah), ${ }^{11} \mathrm{~A}$ (Tubuh Air) 
Tabel 6. Kontribusi terhadap penutupan vegetasi hutan pada lahan terdegradasi

\begin{tabular}{|c|c|c|c|c|c|c|}
\hline \multirow[b]{2}{*}{ No. } & \multirow[b]{2}{*}{ Kondisi Simulasi } & \multirow{2}{*}{$\begin{array}{l}\text { Lahan Terdegradasi } \\
\text { (2013) }\end{array}$} & \multicolumn{2}{|c|}{ Kontribusi Penutupan Vegetasi } & \multirow{2}{*}{$\begin{array}{c}\text { Kategori } \\
\text { Lahan Kritis } \\
\text { (P.32/Menhut-II/09) }\end{array}$} & \multirow[b]{2}{*}{ Skor } \\
\hline & & & Luas (ha) & $\%$ & & \\
\hline 1 & Skenario 0 & 27,877 & 7,627 & 27.36 & Buruk & 100 \\
\hline 2 & Skenario 1 & 27,877 & 11,952 & 42.87 & Sedang & 150 \\
\hline
\end{tabular}

\section{SIMPULAN}

Model perubahan penggunaan lahan menggunakan CLUE-S untuk mempertahankan proporsi luas hutan sebesar $30 \%$ sampai akhir proyeksi tahun 2033 sebagaimana disyaratkan dalam penyusunan pola ruang berdasarkan UU No 26 Tahun 2007 tentang Penataan Ruang adalah dengan menerapkan kebijakan larangan konversi lahan pada hutan primer dan lahan gambut serta pengalokasian rehabilitasi hutan pada lahan sangat kritis.

\section{UCAPAN TERIMA KASIH}

Ucapan terima kasih kepada Pusdiklatren BAPPENAS RI yang telah membiayai penelitian ini melalui anggaran Beasiswa BAPPENAS tahun 2014, kepada Institut for Environmental Studies, Universitas Amsterdam atas pengembangan perangkat lunak Dyna CLUE-S v2.0 yang dapat digunakan secara terbuka dan Bupati Humbang Hasundutan beserta jajarannya atas izin penelitian dan bantuan data-data dalam penelitian.

\section{DAFTAR PUSTAKA}

[BPDAS] Balai Pengelolaan Daerah Aliran Sungai. 2013. Up Dating/ Review Lahan Kritis Wilayah Kerja BPDAS Wampu Sei Ular. Balai Pengelolaan Daerah Aliran Sungai Wampu Sei Ular, Medan.

[BPS] Badan Pusat Statistik. 2013. Kabupaten Humbang Hasundutan dalam Angka. Humbang Hasundutan, Doloksanggul.

[Dishutlindup] Dinas Kehutanan dan Lingkungan Hidup. 2013. Rencana Pengelolaan Rehabilitasi Hutan dan Lahan Tahun 2013-2017. Dinas Kehutanan dan Lingkungan Hidup Kabupaten Humbang Hasundutan, Doloksanggul.
[Kemenlinghut] Kementerian Lingkungan Hidup dan Kehutanan. 2015. Keputusan Menteri Kehutanan dan Lingkungan Hidup Nomor : SK. 2312/MenhutVII/ IPSDH/ 2015 tentang Penetapan Peta Indikatif Penundaan Izin Baru Pemanfaatan Hutan, Penggunaan Kawasan dan Perubahan Peruntukan Kawasan Hutan dan Areal Penggunaan Lain (Revisi VIII). Kementerian Lingkungan Hidup dan Kehutanan RI, Jakarta.

Kim, I., G.Y. Jeong, S. Park, and J. Tenhunen. 2011. Predicted Land Use Change in the Soyang River Basin. 2011 Terreco Science Conference. Karlsruhe Institute of Technology, Garmisch-Partenkirchen, Germany. p. 17-24.

Pontius, R.G., and L.C. Schneider. 2001. Land-cover change model validation by an ROC method for the Ipswich watershed, Massachusetts, USA. Agriculture, Ecosystems \& Environment, 85: 239248 .

Rossiter, D.G. 1996. A theoretical framework for land evaluation. Geoderma, 72: 165-190.

Veldkamp, A., and L.O. Fresco. 1996. CLUE-CR: An integrated multi-scale model to simulate land use change scenarios in Costa Rica. Ecological Modeling, 91:231-248.

Veldkamp, A., and E. Lambin. 2001. Predicting land-use change. Agriculture, Ecosystems \& Environment, 85: 1-6.

Verburg, P.H., W. Soepboer, A. Veldkamp, R. Limpiada, V. Espaldon, and S.S.A. Mastura. 2002. Modelling the spatial dynamics of regional land uses: The CLUE-S model. Environmental Management, 30:391-405.

Verburg, P.H. 2010. The CLUE Modelling Framework. Course Material. University of Asterdam, Amsterdam. 